\title{
Fractography and Crack Initiation of Very-High-Cycle Fatigue for a High Carbon Low Alloy Steel
}

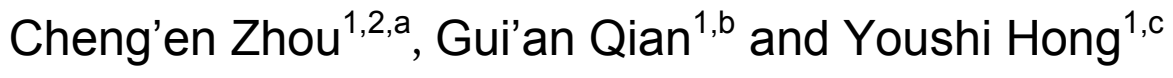 \\ ${ }^{1}$ State Key Laboratory of Nonlinear Mechanics (LNM), Institute of Mechanics, \\ Chinese Academy of Sciences, Beijing 100080, China \\ ${ }^{2}$ College of Science, Inner Mongolia University of Technology, Huhhot 010051, China \\ azce@Inm.imech.ac.cn, bqga@Inm.imech.ac.cn, chongys@imech.ac.cn
}

Key words: fractography, very-high-cycle fatigue, crack initiation

\begin{abstract}
Very-High-Cycle Fatigue (VHCF) is the phenomenon of fatigue damage and failure of metallic materials or structures subjected to $10^{8}$ cycles of fatigue loading and beyond. This paper attempts to investigate the VHCF behavior and mechanism of a high strength low alloy steel (main composition: $\mathrm{C}-1 \%$ and $\mathrm{Cr}-1.5 \%$; quenched at $1108 \mathrm{~K}$ and tempered at $453 \mathrm{~K}$ ). The fractography of fatigue failure was observed by optical microscopy and scanning electron microscopy. The observations reveal that, for the number of cycles to fatigue failure between $10^{6}$ and $4 \times 10^{8}$ cycles, fatigue cracks almost initiated in the interior of specimen and originated at non-metallic inclusions. An "optical dark area" (ODA) around initiation site is observed when fatigue initiation from interior. ODA size increases with the decrease of fatigue stress, and becomes more roundness. Fracture mechanics analysis gives the stress intensity factor of ODA, which is nearly equivalent to the corresponding fatigue threshold of the test material. The results indicate that the fatigue life of specimens with crack origin at the interior of specimen is longer than that with crack origin at specimen surface. The experimental results and the fatigue mechanism were further analyzed in terms of fracture mechanics and fracture physics, suggesting that the primary propagation of fatigue crack within the fish-eye local region is the main characteristics of VHCF.
\end{abstract}

\section{Introduction}

With regard to the advancement of society and the development of technology, a variety of engineering structures and their components, such as flying vehicles, automobiles, ships, railway, bridges, etc., should be able to endure $10^{8}$ loading cycles or more of safe performance. Therefore, the VHCF has attracted much attention nowadays.

Generally speaking, ordinary fatigue crack initiation occurs mostly on the specimen surface due to slip deformation of crystals or surface defects. Recent studies reported that inclusions cause fish-eye fracture in fatigue of high strength steels ${ }^{[1,2,3]}$. The fish-eye fracture is an internally originating type of fatigue failure, which eliminates the traditional fatigue limit of high strength steels. Hence, inclusions decrease the fatigue strength of high strength steels and cause $\mathrm{VHCF}^{[4,5]}$. This paper attempts to further investigate the behavior and mechanism of VHCF for metallic materials. A high carbon low alloy steel was studied for this purpose.

\section{Experiment procedure}

The material used in the present study was a bearing steel. The chemical compositions of the material were as follows (wt \%): C 1\%, Cr 1.5\% and Fe balance. The specimens were heated at $1108 \mathrm{~K}$ then quenched in oil, followed by tempering at $453 \mathrm{~K}$ for 2 hours. The yield stress of specimen was 1900MPa. The specimen for fatigue testing was hour-glass type with the minimum section diameter 
of $3 \mathrm{~mm}$ as shown in Fig.1. Fatigue test was conducted in cantilever-type rotating bending fatigue machines operated at the frequency of $52.5 \mathrm{~Hz}$ at room temperature in laboratory air. The stress ratio of the maximum to minimum load was -1 .

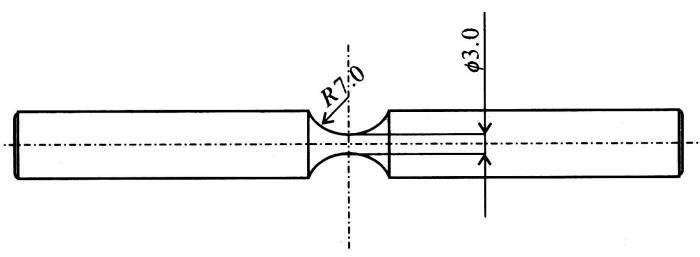

Fig. 1 Shape and dimensions of specimen ( $\mathrm{mm})$.

\section{S-N Curve}

Figure 2 presents S-N data of the specimens. Based on SEM observations of the fracture surfaces, each specimen was classified into one of two groups: (i) surface-induced fracture and (ii) interior inclusion-induced fracture with a fish-eye. For the latter group, there were two cases: either the fish-eye was near the surface or the isolated fish-eye appeared inside the fracture surface as shown later.

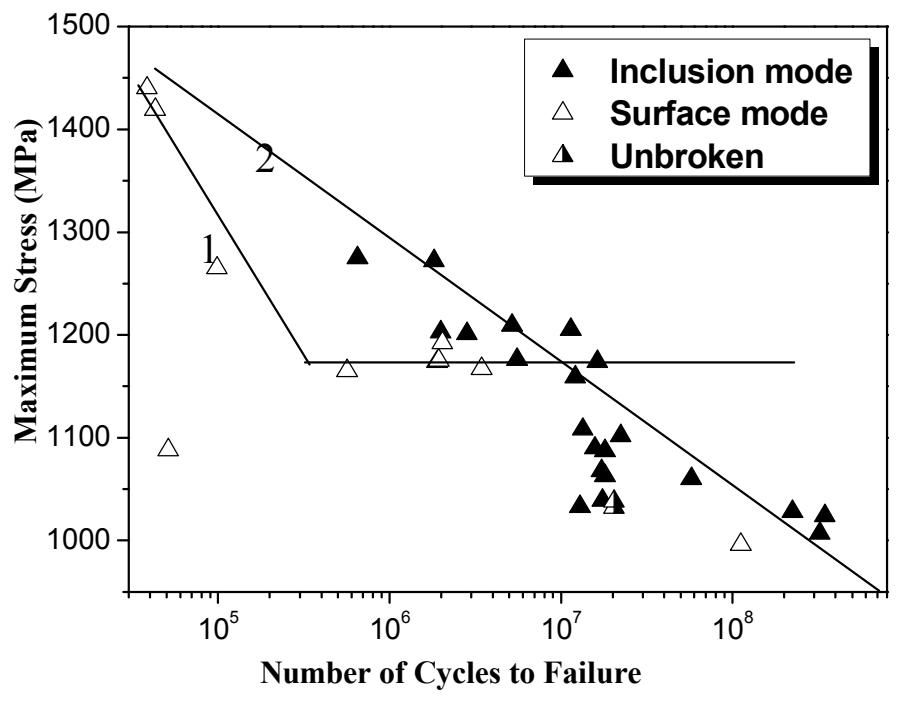

Fig.2 S-N curve $(f=52.5 \mathrm{~Hz}, R=-1)$

At higher stress levels, fatigue fracture tends to occur in the surface-induced fracture mode, whereas inclusion-induced fracture with fish-eye is apt to take place at low stress levels. Isolated fish-eyes inside the fracture surface tend to appear at low stress levels, whereas the other type of fish-eyes, in contact with the surface, tends to appear at relatively high stress levels. The overall trend of the S-N characteristics is well explained as a duplex S-N behavior consisting of the respective S-N curves for the surface-induced fracture and the interior inclusion-induced fracture.

As clearly seen in Fig 2, the S-N curve is duplex: one for surfaced fatigue and the other for internal fatigue. There are two fatigue limits: the surface fatigue limit and the internal fatigue limit. The surface fatigue life is shorter than the internal fatigue life. From the design point of view, it is important that fracture takes place even below surface fatigue limit. 


\section{Scanning electronic microscope observation of fracture surfaces}

Fig. 3 shows the fracture surface of inclusion-induced fracture with a fish-eye. The observation of SEM shows the crack origin is usually the nonmetallic inclusion located underneath the surface. The composition of the inclusion is $\mathrm{Al}_{2} \mathrm{O}_{3}$.

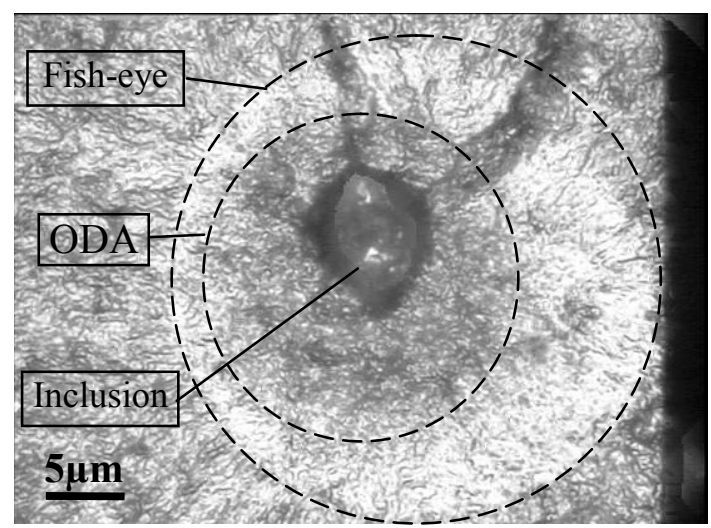

Fig. 3 Different parts of fish-eye

In order to distinguish crack initiation and crack propagation process, the relationship between the corresponding stress intensity factors and the threshold of crack propagation is indicated. The stress intensity factor at the front of ODA or inclusion can be calculated by the following formula.

$$
K_{\text {init }}=M \frac{2}{\pi^{3 / 4}} \sigma \sqrt{\sqrt{\text { Area }}}
$$

where $M$ is the shape factor, $\sigma$ is the stress applied and Area means the area of ODA or inclusion. Fig.4 presents the relationship of $K_{\text {init }}$ and the fatigue cycles. The value of $K_{\text {init }}$ at the front of ODA corresponds with the fatigue threshold of the material. So, it is appropriate that the boundary of ODA is regarded as the division of fatigue initiation and fatigue propagation. For internal fatigue with long lives, most of the fatigue life was spent for crack initiation.

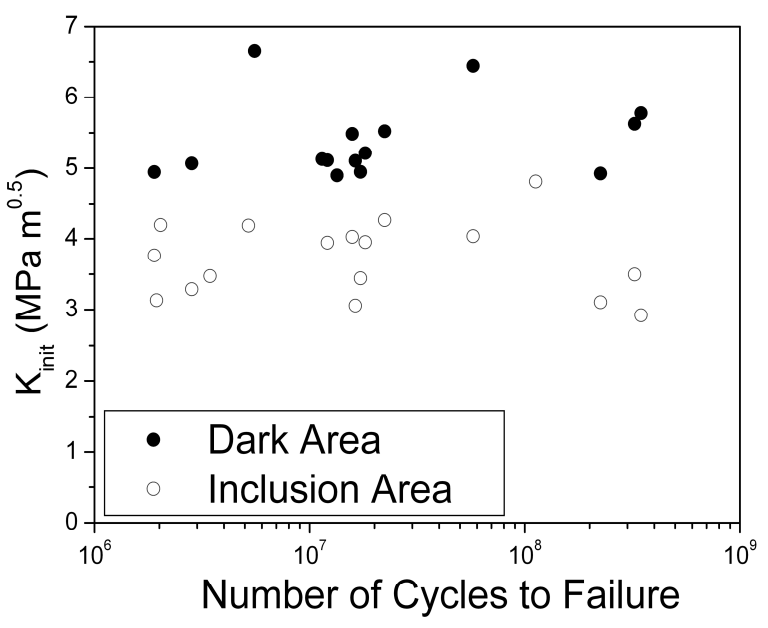

Fig. 4 Correlation between $K_{\text {init }}$ and fatigue cycles 
Fig.5 shows the relationships between the area of inclusion, the area of ODA and the value of $R_{O D A} / R_{\text {inclusion }}$ and the cycles to failure. It is surprising that the area of ODA and the value of $R_{O D A} / R_{\text {inclusion }}$ increased with increasing fatigue life, whereas the area of ODA has no direct relationship with fatigue life.

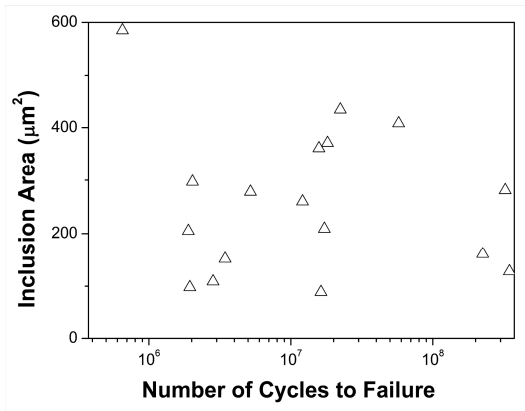

(a)

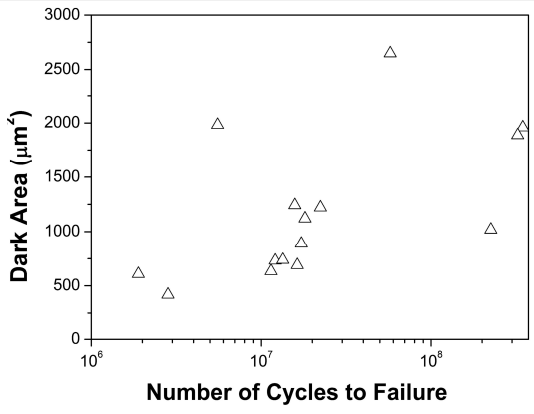

(b)

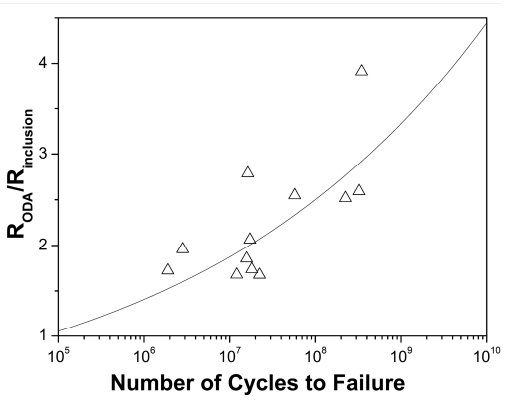

(c)

Fig.5 Relationships between inclusion area, dark area, $\mathrm{R}_{\mathrm{ODA}} / \mathrm{R}_{\text {inclusion }}$ and number of cycles to failure

\section{Conclusions}

The S-N curve of high alloy steel is duplex. For internal fatigue with long lives, a fish-eye was seen in fracture surface, and an optical dark area (ODA) was always observed in the vicinity around the inclusion. The area of ODA monotonically increased with increasing fatigue life. The formation of ODA corresponds with the crack initiation process.

\section{Acknowledgements}

This paper was supported by the National Natural Science foundation of China (10472117), and the Chinese Academy of Sciences.

\section{References}

[1] Wang Q Y, Berard J Y, Dubarre A, et al. Gigacycle fatigue of ferrous alloys. Fatigue Fract. Engng. Mater. Struct., 1999, 22: 667-672.

[2] Chapetti M D, Tagawa T, Miyata T. Ultra-long cycle fatigue of high-strength carbon steels part II: estimation of fatigue limit for failure from internal inclusions. Materials Science and Engineering A, 2003, 356(1-2): 236-244.

[3] Sakai T, Takeda M, et al. Experimental evidence of duplex S-N characteristics in wide life region for high strength steels. In: Wu X R, Wang Z G eds., proceedings of the 7th International Fatigue Congress, Beijing, 1999. 573-578.

[4] Murakami Y, Yokoyama N N, Nagata J. Mechanism of fatigue failure in ultra long life regime. Fatigue Fract. Engng. Mater. Struct., 2002, 25: 735-746.

[5] Bathias C. There is no infinite fatigue life in metallic materials. Fatigue Fract. Engng. Mater. Struct., 1999, 22: 559-565. 